\title{
Anti-invasive effects of decitabine, a DNA methyltransferase inhibitor, through tightening of tight junctions and inhibition of matrix metalloproteinase activities in AGS human gastric carcinoma cells
}

\author{
DONG YEOK SHIN ${ }^{1,2}$, GI-YOUNG KIM ${ }^{3}$, CHAN GIL KIM ${ }^{4}$, \\ WUN-JAE KIM ${ }^{5}$, HO SUNG KANG ${ }^{2}$ and YUNG HYUN CHOI ${ }^{1,6}$ \\ ${ }^{1}$ Department of Biochemistry, Dongeui University College of Oriental Medicine, Busan 614-052; \\ ${ }^{2}$ Department of Molecular Biology, Pusan National University, Busan 609-735; ${ }^{3}$ Laboratory of Immunobiology, \\ Department of Marine Life Sciences, Jeju National University, Jeju 690-756; ${ }^{4}$ Department of Biotechnology, \\ Konkuk University, Chungju 380-701; ${ }^{5}$ Department of Urology, Chungbuk National University College \\ of Medicine, Cheongju 361-763; ${ }^{6}$ Department of Biomaterial Control (BK21 program), Graduate \\ School and Blue-Bio Industry RIC, Dongeui University, Busan 614-714, Republic of Korea
}

Received February 20, 2012; Accepted April 27, 2012

DOI: 10.3892/or.2012.1858

\begin{abstract}
The DNA methyltransferase inhibitor decitabine, 5-Aza-2'-deoxycytidine, possesses anti-metabolic and anticancer activities in various cancer cells. However, the biochemical mechanisms underlying decitabine-induced inhibition of invasiveness and metastasis have not been thoroughly studied. In this study, we investigated the effect of decitabine on the correlation between tightening of tight junctions (TJs) and anti-invasive activity in AGS human gastric cancer cells. Our data indicated that the inhibitory effects of decitabine on cell motility and invasiveness were associated with increased tightness of the TJ, which was demonstrated by an increase in transepithelial electrical resistance (TER). Immunoblotting results indicated that decitabine repressed the levels of the claudin proteins, major components of TJs that play a key role in the control and selectivity of paracellular transport. Furthermore, matrix metalloproteinase (MMP)-2 and -9 activity in the AGS cells was dose-dependently inhibited by treatment with decitabine, and this was correlated with a decrease in mRNA and protein expression. In addition, these effects were related to inactivation of the phosphoinositide 3-kinase (PI3K)/Akt pathway in AGS cells. In conclusion,
\end{abstract}

Correspondence to: Dr Ho Sung Kang, Department of Molecular Biology, Pusan National University, Busan 609-735, Republic of Korea

E-mail: hspkang@pusan.ac.kr

Dr Yung Hyun Choi, Department of Biochemistry, Dongeui University College of Oriental Medicine, Busan 614-052, Republic of Korea

E-mail: choiyh@deu.ac.kr

Key words: decitabine, invasion, tight junctions, MMPs, PI3K/Akt this study suggests that TJs and MMPs are critical targets of decitabine-induced inhibition of invasiveness in AGS human gastric cancer cells.

\section{Introduction}

Metastasis is a sequential multi-step process that includes cell migration and cell invasion, important participants in the progression of the cancerous process. In general, metastasis involves four major steps: adhesion of tumor cells to the extracellular matrix (ECM), the ability of tumor cells to degrade the ECM and intravasate into surrounding blood vessels, survival against the natural host defenses and settling at the preferred organ site, and extravasation into the organ and formation of new tumors $(1,2)$. Therefore, inhibition of metastasis including tumor cell migration and invasion is an important mechanism in the anti-metastatic properties of anti-cancer drugs.

Cell adhesion between neighboring epithelial cells involving tight junctions (TJs), gap junctions, and adherens junctions is a crucial and tightly controlled process. TJs represent one mode of cell-to-cell adhesion in epithelial or endothelial cells. In addition, TJs are the first barrier, providing a physical barrier to paracellular transport of solutes across cells and playing a critical role in establishing and maintaining epithelial cell polarity. In the cancerous condition and cancerous lesions of epithelium origin, TJ strands become disorganized or lost altogether, and TJs become 'leaky', as indicated by decreased resistance to electrical current (transepithelial electrical resistance; TER) and the increased paracellular permeability of markers $(3,4)$. Claudins are key integral membrane proteins, the most important components of the TJs, and can form homodimers or heterodimers to produce paired strands between adjacent cells and act as a barrier to paracellular flux of water, solutions, and transmigration of other cells, thereby determining the characteristic 
permeability properties of different epithelial tissues. Claudins have four transmembrane domains, with the $\mathrm{N}$-terminus and the C-terminus in the cytoplasm $(5,6)$. Recently, researchers have reported overexpression of claudins in metastatic gastric cancer and in other cancers (6-10) and the inhibition of claudin expression reduced the cancer invasive potential in ovarian cancer cells (11-13). Although the exact functional importance of the overexpressed claudins in cancers remains unclear, these observations indicate that claudins have key cellular functions during the metastasis process.

Matrix metalloproteinases (MMPs) are a family of zincdependent endopeptidases that process a broad spectrum of cell surface molecules and function in several important biological processes. MMPs are also collectively capable of cleaving virtually all ECM substrates, and play an important role in cancer progression, invasion, and metastasis $(14,15)$. MMP-2 (gelatinase-A) and MMP-9 (gelatinase-B) are included in proteolytic degradation of the basement membrane by degrading type IV collagen. In addition, it has been reported that MMP-2 and -9 are overexpressed in gastric cancer areas compared to normal areas, and high expression is a negative prognostic factor in gastric cancer $(16,17)$.

Various models have been studied showning epigenetic regulation is essential for cancer progression. Among them, decitabine (5-Aza-2'-deoxycytidine), a DNA methyltransferase inhibitor (DNMTI), is critical for epigenetic regulation through DNA hypermethylation and hypomethylation in cancer $(1,18)$. Aberrant methylation is one of the more frequent molecular changes observed in tumor cells and typically involves the reversal of normal methylation patterns $(19,20)$. Common changes involve genome-wide hypomethylation, which impinges on the expression of oncogenes, loss of imprinting, and hypermethylation of tumor suppressor genes $(21,22)$. Several recent studies have indicated that decitabine also inhibits cancer cell growth and induces apoptotic cell death $(23,24)$. However, the precise biochemical mechanisms underlying decitabine-induced anti-metastasis have not yet been clarified. Therefore, the present study attempted to elucidate the anti-metastatic potential of decitabine and underlying intracellular signal transduction pathways involved in inhibiting metastasis of human gastric carcinoma AGS cells.

\section{Materials and methods}

Cell culture and MTT assay. The human gastric carcinoma AGS cell line was purchased from the American Type Culture Collection (Rockville, MD). AGS cells were cultured in RPMI-1640 medium (Gibco/BRL, Gaithersburg, MD) supplemented with $10 \%$ fetal bovine serum (FBS) and $1 \%$ penicillin-streptomycin in a $37^{\circ} \mathrm{C}$ incubator with $5 \% \mathrm{CO}_{2}$. Decitabine was purchased from Sigma Chemical Co. (St. Louis, MO), dissolved in 100\% dimethyl sulfoxide (DMSO) to a stock concentration $10 \mathrm{mM}$, and stored at $-80^{\circ} \mathrm{C}$. For the cell viability study, AGS cells were seeded onto 6 -well plates at a concentration of $5 \times 10^{4}$ cells/well, grown to $70 \%$ confluence, and then treated with various concentrations of decitabine for $48 \mathrm{~h}$. Following treatment, cell viability was determined using the 3-(4,5-dimethylthiazol-2-yl)-2,5-diphenyl-tetrazolium bromide (MTT, Sigma) assay, which is based on the conversion of MTT to MTT-formazan by mitochondrial enzymes.
Wound healing migration assay. AGS cells were grown to confluence on 30-mm cell culture dishes coated with rat tail collagen $(20 \mu \mathrm{g} / \mathrm{ml}$, BD Biosciences, Bedford, MA). A scratch was made in the cell layer with a pipette tip. After the cells were washed with PBS, serum-free media (to prevent cell proliferation) containing $20 \mu \mathrm{M}$ of decitabine was added. Photographs of the wounded area were taken immediately after the scratch was made and at 12, 24 and $48 \mathrm{~h}$ to monitor cell movement into the wounded area (25).

In vitro invasiveness assay. Matrigel invasion assays were used to assess the ability of AGS cells to penetrate the ECM in the presence or absence of decitabine. Briefly, cells were exposed to 10 and $20 \mu \mathrm{M}$ of decitabine for $6 \mathrm{~h}$, and treated cells $(50,000)$ were then plated onto the apical side of the Matrigelcoated filters in serum-free medium containing 10 and $20 \mu \mathrm{M}$ of decitabine. Medium containing $20 \%$ FBS was placed in the basolateral chamber to function as a chemoattractant. After $48 \mathrm{~h}$, cells on the apical side were wiped off with a Q-tip. Cells on the bottom of the filter were stained with hematoxylin and eosin Y (Sigma) and counted (three fields of each triplicate filter) using an inverted microscope.

Measurement of TER. TER was measured with an EVOM Epithelial Tissue Voltohmmeter (World Precision Instruments, Sarasota, City, FL), equipped with a pair of STX-2 chopstick electrodes. Briefly, AGS cells were seeded into the $8.0 \mu \mathrm{m}$ pore size insert (upper chamber) of a Transwell (Corning Costar Corp., Cambridge MA) and allowed to reach full confluence, after which fresh medium was replaced for additional experiments. Inserts without cells, inserts with cells in medium, and inserts with cells with 10 and $20 \mu \mathrm{M}$ of decitabine were treated for $48 \mathrm{~h}$. Electrodes were placed at the upper and lower chambers, and resistance was measured with the voltohmmeter (26).

RNA extraction and reverse transcription-polymerase chain reaction. Total RNA was prepared using an RNeasy kit (Qiagen, La Jolla, CA) and primed with random hexamers to synthesize complementary DNA using AMV reverse transcriptase (Amersham Co., Arlington Heights, IL), according to the manufacturer's instructions using DNAse I (1 U/ $\mu$ g RNA) pretreated total mRNA. Polymerase chain reaction (PCR) was carried out in a Mastercycler (Eppendorf, Hamburg, Germany) using the desired primers. The conditions for the PCR reactions were 1 cycle $\left(94^{\circ} \mathrm{C}\right.$ for $\left.3 \mathrm{~min}\right), 35$ cycles $\left(94^{\circ} \mathrm{C}\right.$ for $45 \mathrm{sec}$; $58^{\circ} \mathrm{C}$ for $45 \mathrm{sec}$; and $72^{\circ} \mathrm{C}$ for $\left.1 \mathrm{~min}\right)$, and 1 cycle $\left(72^{\circ} \mathrm{C}\right.$ for $10 \mathrm{~min})$. Amplification products obtained with PCR were electrophoretically separated on $1 \%$ agarose gel and visualized with ethidium bromide (EtBr) staining.

Protein extraction and western blot analysis. Total cell lysates from decitabine-treated cells were prepared in an extraction buffer [25 mM Tris- $\mathrm{Cl}$ ( $\mathrm{pH} 7.5$ ), $250 \mathrm{mM} \mathrm{NaCl}, 5 \mathrm{mM}$ ethylendiaminetetra acetic acid, $1 \%$ Nonidet P-40, $0.1 \mathrm{mM}$ sodium orthovanadate, $2 \mu \mathrm{g} / \mathrm{ml}$ leupeptin, and $100 \mu \mathrm{g} / \mathrm{ml}$ phenylmethylsulfonyl fluoride]. Protein concentration was determined using a Bio-Rad protein assay kit (Bio-Rad, Laboratories, Hercules, CA). For western blot analysis, proteins $(50 \mu \mathrm{g})$ were separated with $8-13 \%$ sodium dodecyl sulfate (SDS)- 


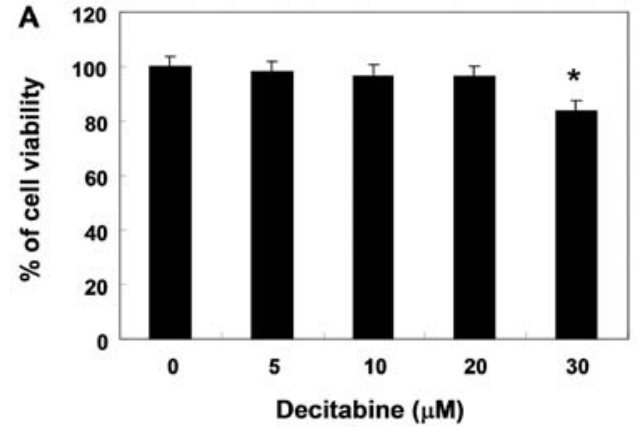

B

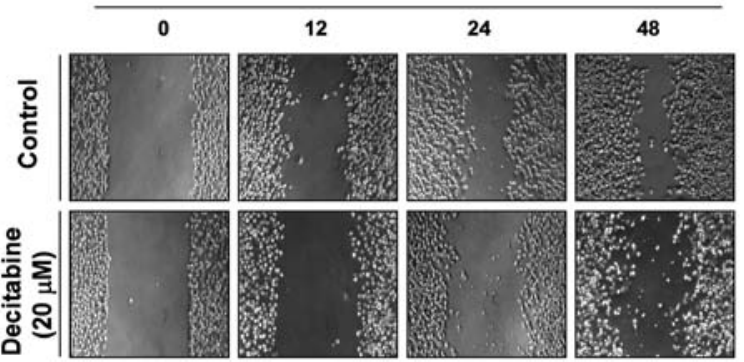

Figure 1. Effects of decitabine on cell viability and motility in AGS cells. (A) Cells were seeded at an initial density of $2.5 \times 10^{5}$ cells per $60-\mathrm{mm}$ plate, incubated for $24 \mathrm{~h}$, and treated with various concentrations of decitabine for $48 \mathrm{~h}$. Cell viability was measured using an MTT assay. Each point represents the mean $\pm \mathrm{SD}$ of three independent experiments. A Student's t-test was used to determine significance ("P $<0.05$ vs. untreated control). (B) Cells were grown to confluency on 30-mm cell culture dishes; a scratch was then made through the cell layer using a pipette tip. After the cells were washed with PBS, serum-free media (to prevent cell proliferation) containing either vehicle or decitabine $(20 \mu \mathrm{M})$ was added for the indicated times. Photographs of the wounded area were taken to evaluate cell movement into the wounded area.

polyacrylamide gel electrophoresis and then electrotransferred to a nitrocellulose membrane (Schleicher \& Schuell, Keene, $\mathrm{NH}$ ). Membranes were blocked with $5 \%$ skim milk for $1 \mathrm{~h}$, and then subjected to immunoblot analysis using the desired antibodies. Proteins were then visualized with the enhanced chemiluminescence (ECL) method, according to the recommended procedure (Amersham Co.). Primary antibodies were purchased from Santa Cruz Biotechnology Inc. (Santa Cruz, CA) and Calbiochem (Cambridge, MA). Peroxidase-labeled donkey anti-rabbit immunoglobulin and peroxidase-labeled sheep anti-mouse immunoglobulin were purchased from Amersham Co.

Gelatin zymographic analysis of secreted MMPs. Following incubation with various concentrations of decitabine for $48 \mathrm{~h}$, cell culture supernatants were collected and centrifuged at $400 \mathrm{x}$ g for $5 \mathrm{~min}$. Cell-free supernatant was mixed with $2 \mathrm{X}$ sample buffer (Invitrogen, Grand Island, NY), and zymography was performed using precast gels $(10 \%$ polyacrylamide and $0.1 \%$ gelatin). Following electrophoresis, the gels were washed twice at room temperature for $30 \mathrm{~min}$ in $2.5 \%$ Triton $\mathrm{X}-100$, subsequently washed in buffer containing $50 \mathrm{mM}$ Tris- $\mathrm{HCl}, 150 \mathrm{mM} \mathrm{NaCl}, 5 \mathrm{mM} \mathrm{CaCl}{ }_{2}, 1 \mu \mathrm{M} \mathrm{ZnCl}_{2}$, and $0.02 \% \mathrm{NaN}_{3}$ at $\mathrm{pH} 7.5$, and incubated in this buffer at $37^{\circ} \mathrm{C}$ for $24 \mathrm{~h}$. Thereafter, the gels were stained with $0.5 \%(\mathrm{w} / \mathrm{v})$ Coomassie Brilliant Blue G250 (Bio-Rad) for $1 \mathrm{~h}$ and then lightly destained in methanol:acetic acid:water (3:1:6). Clear
A

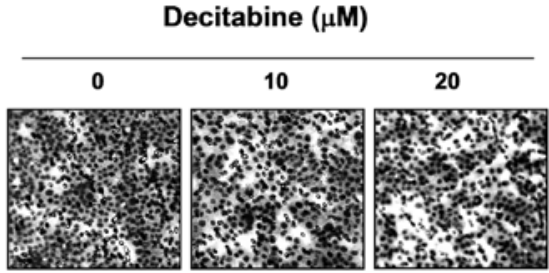

B

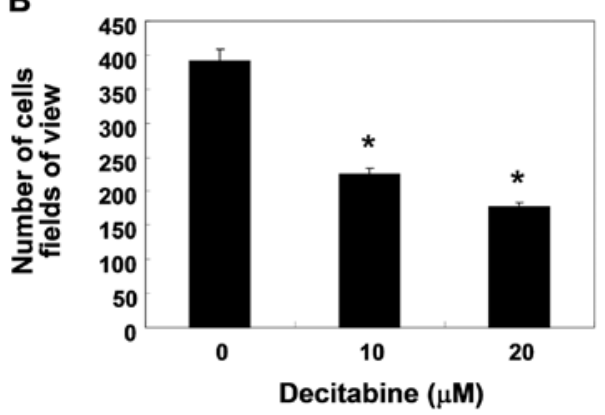

Figure 2. Decrease in cell invasion by decitabine in AGS cells. Cells pretreated with 10 or $20 \mu \mathrm{M}$ decitabine for $6 \mathrm{~h}$ were plated onto the apical side of matrigel-coated filters in serum-free medium containing either vehicle or decitabine. Medium containing 20\% FBS was placed in the basolateral chamber to act as a chemoattractant. After $48 \mathrm{~h}$, cells on the apical side were wiped off using a Q-tip. Next, cells on the bottom of the filter were stained using hematoxylin and eosin Y (A), and then counted (B). Data are shown as the mean of triplicate samples and represent invasive cell numbers compared with those of control cells. ${ }^{*} \mathrm{P}<0.05$ vs. untreated control.

bands appear on the Coomassie stained blue background in areas of gelatinolytic activity. The gels were scanned, and the images were processed by extracting the blue channel signal, converting it to black and white, and inverting it to quantify the gelatinolytic activities from the integrated optical density (27).

Statistical analysis. All data are presented as mean \pm SD. Significant differences among the groups were determined using the unpaired Student's t-test. A value of $\mathrm{P}<0.05$ was accepted as an indication of statistical significance. All of the figures shown in this article were obtained from at least three independent experiments.

\section{Results}

Effects of decitabine on cell viability and cell migration in AGS cells. To determine the effect of decitabine on cell viability in AGS cells, an MTT assay was performed at $48 \mathrm{~h}$ after treatment with the indicated concentrations $(5-30 \mu \mathrm{M})$ of decitabine. Decitabine alone in the range of 5-20 M mg/ $\mathrm{ml}$ did not have any cytotoxic effect on AGS cells, whereas a high concentration of decitabine $(30 \mu \mathrm{M})$ significantly caused a decrease in cell viability. When compared with the control, treatment with $30 \mu \mathrm{M}$ of decitabine caused approximately $15 \%$ inhibition of cell growth (Fig. 1A). Therefore, we applied $20 \mu \mathrm{M}$ decitabine for the optimal treatment concentration to investigate whether decitabine decreases cell migration in AGS cells. The wound healing assay results demonstrated that treatment with $20 \mu \mathrm{M}$ decitabine timedependently delayed cell motility, when compared with controls (Fig. 1B). 
A

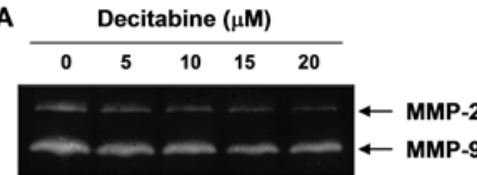

B

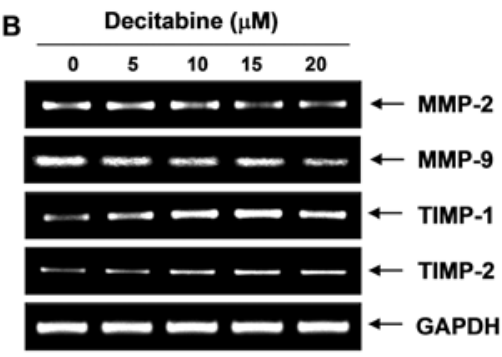

C

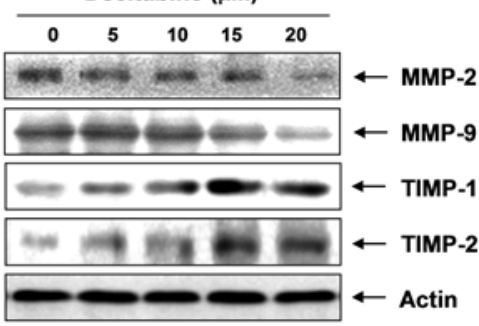

Figure 3. Inhibition of MMP expression and their activities, and induction of TIMP expression by decitabine in AGS cells. (A) Cells were treated with the indicated concentrations of decitabine for $48 \mathrm{~h}$. The medium was collected, and MMP-2 and -9 activity was measured with zymography. (B) After incubation with decitabine under the same conditions as those of $\mathrm{A}$, total RNA was isolated and reverse-transcribed. The resulting cDNAs were then subjected to PCR. The reaction products were subjected to electrophoresis in a $1 \%$ agarose gel and visualized with EtBr staining. GAPDH was used as an internal control. (C) Cells grown under the same conditions as (A) were sampled and lysed, and $50 \mu \mathrm{g}$ of proteins were separated by electrophoresis on SDS-polyacrylamide gels. Western blotting was then performed using the indicated antibodies and an ECL detection system. Actin was used as an internal control.

Inhibition of cell invasion by decitabine in AGS cells. Because cancer invasion is the initial step in metastasis in destroying the basement membrane, we then used a Boyden chamber invasion assay to determine whether the inhibitory effects of decitabine were connected to the decreased activity of cell invasion. As shown in Fig. 2, decitabine treatment resulted in markedly reduced cell invasion through the Matrigel chamber in a concentration-dependent manner, suggesting the inhibitory effects of cell migration were associated with inhibition of invasive activity in AGS cells.

Inhibition of the activity and expression of MMP-2 and $M M P-9$ by decitabine in AGS cells. Because migration influences metastasis and invasion of the basement membrane is primarily mediated by gelatinase MMPs, we tested the effects of decitabine on the activation and expression of MMPs using gelatin zymography, RT-PCR and western blot analyses. Data indicated MMP-2 and MMP-9 activity in AGS cells was decreased by decitabine treatment, which was connected to concurrent downregulation of the mRNA and protein levels (Fig. 3). In addition to the MMP roles, tissue inhibitors of metalloproteinases (TIMPs) are naturally occurring inhibitors of MMPs, which inhibit MMP catalytic activity through binding to activated MMPs and controlling the breakdown of the ECM. Therefore, we tested the effects of decitabine on

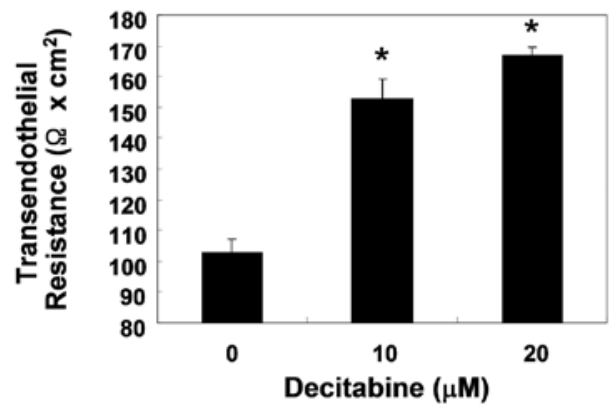

Figure 4. Increase in TER values by decitabine in AGS cells. Cells were treated with 10 or $20 \mu \mathrm{M}$ of decitabine for $48 \mathrm{~h}$, and TER values were measured using an EVOM Epithelial Tissue Voltohmmeter, as described in Materials and methods. Results are shown as the mean \pm SD of three independent experiments. A Student's t-test was used to determine significance $\left({ }^{*} \mathrm{P}<0.05\right.$ vs. untreated control)

A

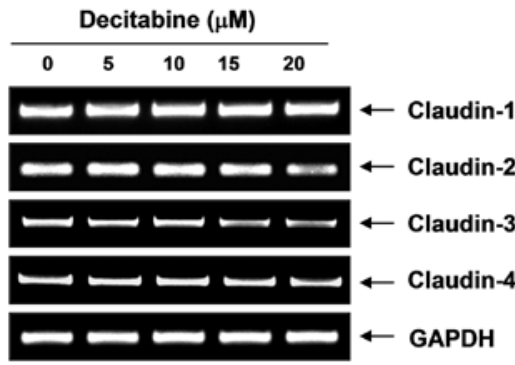

B

Decitabine $(\mu \mathrm{M})$

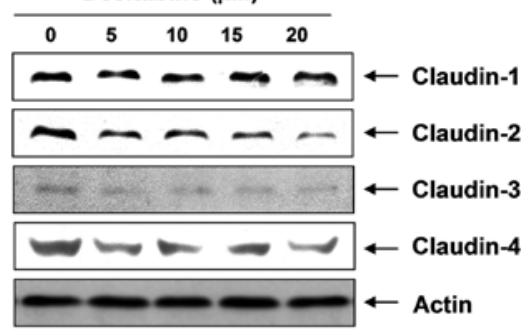

Figure 5. Effects of decitabine on expression of claudins in AGS cells (A) Cells were treated with the indicated concentrations of decitabine for $48 \mathrm{~h}$. Total RNA was isolated and reverse-transcribed using the indicated primers. The resulting cDNAs were then subjected to PCR, and the reaction products were subjected to electrophoresis in a $1 \%$ agarose gel and visualized with EtBr staining. GAPDH was used as an internal control. (B) Cells grown under the same conditions as (A) were sampled and lysed, and $50 \mu \mathrm{g}$ of proteins were separated by electrophoresis on SDS-polyacrylamide gels. Western blotting was then performed using the indicated antibodies and an ECL detection system. Actin was used as an internal control.

TIMP-1 and TIMP-2 expression levels. The RT-PCR results showed decitabine induced a concentration-dependent increase in TIMP-1 and TIMP-2 mRNA levels, which was connected to concurrent upregulation of their protein levels, as determined with western blotting (Fig. 3), suggesting increasing TIMP proteins with decitabine could inhibit MMP activity.

Enhancement of TJs tightening by decitabine in AGS cells. To examine the relationship between TJs tightening and the invasive activity of AGS cells treated with decitabine, TER (a measure of tight junction formation) values were measured using an EVOM epithelial tissue voltohmmeter. As shown in Fig. 4, incubation of cells with decitabine resulted in a substan- 
A
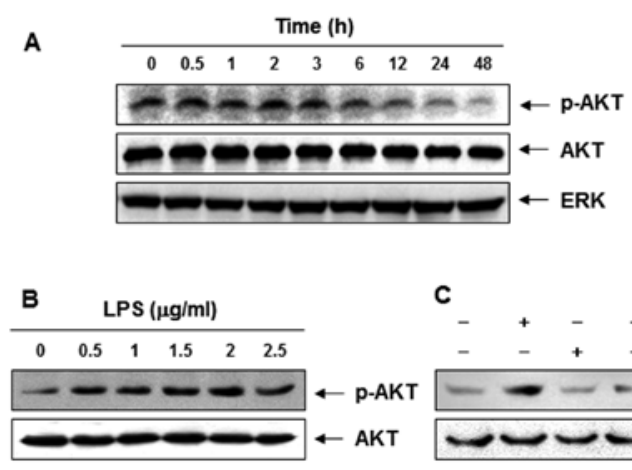

$C_{-}+-+\operatorname{LPS}(2 \mu \mathrm{g} / \mathrm{ml})$

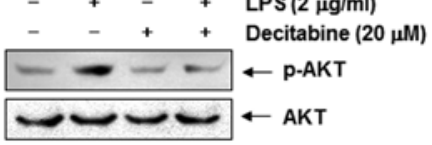

D

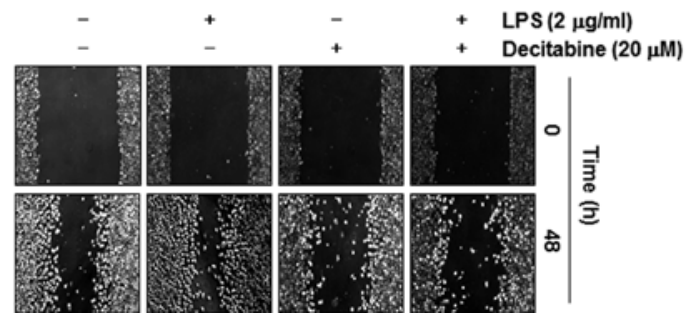

Figure 6. Involvement of the PI3K/Akt pathway in decitabine-induced inhibition of cell motility in AGS cells. (A and B) Cells were treated with $20 \mu \mathrm{M}$ decitabine for the indicated times (A) or treated with the indicated concentrations of LPS for $48 \mathrm{~h}$ (B). The cells were sampled and lysed, and the cellular proteins $(50 \mu \mathrm{g})$ were separated by electrophoresis on SDS-polyacrylamide gels. Western blotting was then performed using anti-p-Akt and anti-Akt antibodies and an ECL detection system. ERK was used as an internal control. (C and D) Cells were treated with $20 \mu \mathrm{M}$ decitabine for $2 \mathrm{~h}$ before LPS treatment $(2 \mu \mathrm{g} / \mathrm{ml})$ for $48 \mathrm{~h}$. (C) Cell lysates were then prepared, and Western blotting was performed using antibodies specific for p-Akt and Akt. (D) Cells were grown to confluency on 30-mm cell culture dishes; a scratch was then made through the cell layer using a pipette tip. After the cells were washed with PBS, serum-free media (to prevent cell proliferation) containing decitabine $(20 \mu \mathrm{M})$ alone or decitabine $(20 \mu \mathrm{M})$ plus LPS $(2 \mu \mathrm{g} / \mathrm{ml})$ was added for $48 \mathrm{~h}$. Photographs of the wounded area were taken to evaluate cell movement into the wounded area.

tial concentration-dependent increase in their TER values. The data indicated that decitabine induced an increase in TJs function in AGS cells, associated with inhibition of cell invasion.

Modulation of TJ-related factors by decitabine in AGS cells. To elucidate the mechanism by which decitabine enhances TJs activity and reduces invasive activity in AGS cells, we determined the levels of claudins, TJ components, using RT-PCR and western blot analysis. As shown in Fig. 5, the transcriptional and translational levels of claudins (claudin-2, -3 and -4), the most important components of TJs, but not claudin-1, were markedly downregulated in decitabine-treated cells in a dosedependent manner, suggesting this modulation contributed to TJs tightening.

Decitabine-induced anti-invasive activity is associated with dephosphorylation of AKT. Recent studies have implicated phosphoinositide 3-kinase (PI3K)/Akt in regulating MMPs and TJs, which are involved in a number of cellular functions, including cell survival, adhesion, and metastasis $(28,29)$. Therefore, the effects of decitabine on the phosphorylated status of Akt in AGS cells were assessed. Immunoblotting data demonstrated that decitabine treatment markedly decreased
A

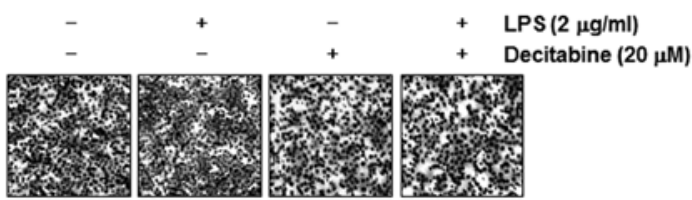

B

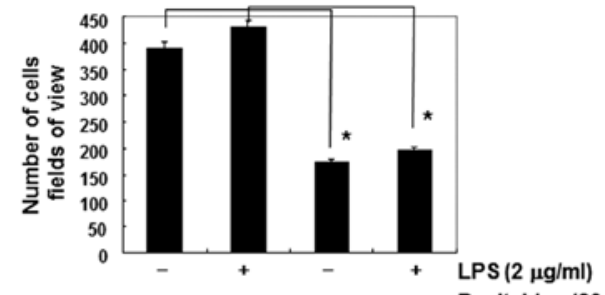

C

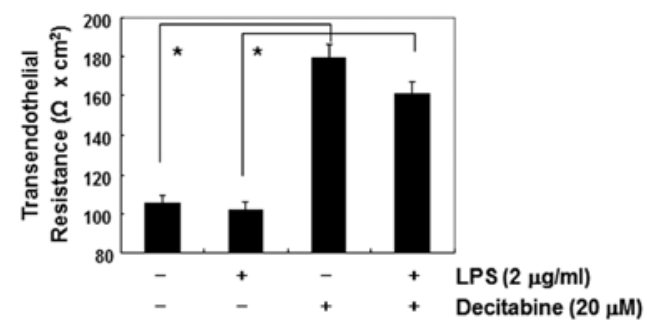

Figure 7. Inhibition of LPS-induced cell invasion by decitabine in AGS cells (A and B) Cells treated with $20 \mu \mathrm{M}$ decitabine for $2 \mathrm{~h}$ before being incubated with LPS for $6 \mathrm{~h}$ were plated onto the apical side of Matrigel-coated filters in serum-free medium containing decitabine $(20 \mu \mathrm{M})$ alone or decitabine $(20 \mu \mathrm{M})$ plus LPS $(2 \mu \mathrm{g} / \mathrm{ml})$. Matrigel invasion assays were used to assess the ability of AGS cells to penetrate the ECM as described in Fig. 2. (C) Cells were treated with $20 \mu \mathrm{M}$ decitabine for $2 \mathrm{~h}$ before LPS treatment $(2 \mu \mathrm{g} / \mathrm{ml})$ for $48 \mathrm{~h}$, and TER values were measured. Results are shown as the mean \pm SD of three independent experiments. Significance was determined using a Student's t-test ( $\mathrm{P}<0.05$ vs. untreated control or LPS treated cells).

the phosphorylation of Akt in a concentration-dependent manner (Fig. 6A). To confirm the involvement of the PI3K/Akt signaling pathway in decitabine-induced anti-invasive activity of AGS cells, we used lipopolysaccharide (LPS) to activate Akt and increase the cell invasion. As shown in Fig. 6B, simulation of AGS cells with LPS led to a concentrationdependent marked increase in the amount of phosphorylated Akt. Consistent with those results, cell motility and invasive activity were partly increased by treatment with LPS. However, the LPS-accentuated increase in Akt phosphorylation, cell motility, and invasive activity was significantly suppressed by decitabine (Figs. 6C and D, and 7A and B). On the contrary, although the TER values in LPS-treated AGS cells were not significantly different from those of the controls, the values were markedly increased in response to decitabine (Fig. 7C).

\section{Discussion}

Because cancer cell invasion and migration are critical steps during metastasis, inhibiting tumor cell migration and invasion are important mechanisms in the anti-metastatic properties of anticancer drugs. The aim of this study was to investigate whether decitabine has potent anti-invasion and anti-metastasis activity in human gastric adenocarcinoma AGS cells. We found that decitabine markedly inhibited cell motility and invasive activity through tightening TJs, and decreasing MMP activity and the Akt signaling pathway. 
MMPs are important proteolytic enzymes during organ development and tissue regeneration; however, they also play important roles in cancer invasion and metastasis. Above all, MMP-2 and MMP-9 play the most important roles in tumor invasion and angiogenesis; therefore, tumor metastasis can be inhibited by blocking MMP synthesis and activity $(30,31)$. MMP activity is tightly controlled by transcriptional activation, by a complex proteolytic activation cascade, and by an endogenous system of TIMPs. TIMPs inhibit MMPs by forming 1:1 stoichiometric complexes to regulate matrix turnover $(32,33)$. Because treatment with less than $20 \mu \mathrm{M}$ of decitabine, which was not cytotoxic as determined with the MTT assay, markedly inhibited the cell motility and invasive activity in AGS cells (Figs. 1B and 2), we investigated whether the inhibitory effects of decitabine were associated with the modulation of TIMPs and MMPs expression or their activities. Our results indicated that decitabine induced inhibition of MMP-2 and -9 mRNA and protein levels as well as their enzymatic activities in a concentration-dependent manner but not MMP-9 levels. However, the transcriptional and translational levels of TIMP-1 and TIMP-2 were concentration-dependently upregulated in response to decitabine treatment (Fig. 3). The present data demonstrated that the decitabine-induced inhibition of cell motility and invasion is related to downregulation of MMP-2 and -9 activities through the elevation of TIMP expression. Therefore, our results showed that decitabine may increase the TIMPs/MMPs ratio, as a key factor in regulating the anti-metastatic process, which subsequently blocks the degradation of the ECM and leads to inhibition of cell invasion.

Increasing evidence indicates that suppressing the malignant phenotype of cells in tumorigenesis is an additional and important function of the TJs (34). Moreover, it is becoming increasingly clear that the development of human cancer is frequently associated with the failure of epithelial cells to form TJs and to establish correct apicobasal polarity (35) suggesting that changes in permeability properties and loss of cell polarity are hallmarks of epithelial cell tumorigenesis. Thus, TJs, the structures critical for maintaining these functions in epithelial cells, are modulated in a number of epithelial cancers, including gastric cancer $(3,4)$. These observations indicated that disruption of TJs and dysregulation of their composite proteins play critical roles in cancer progression, invasion, and metastasis. Indeed, early studies have demonstrated that $\mathrm{TJ}$ structures are altered in many epithelial cancers. For example, Soler et al (3) first demonstrated that the TER of colon carcinoma tissue was significantly lower than that of normal colon tissues but showed higher transepithelial paracellular permeability, which confirmed the loss of the TJs. Previous studies have shown many anticancer agents inhibit motility and invasiveness, and act by enhancing transepithelial paracellular permeability (36-41). Therefore, we examined the changes in the TER values to investigate the relationship between the anti-invasive activity and TJs in response to decitabine treatment. Our results clearly showed that treatment with decitabine increased the TER values of AGS cells in a dose-dependent manner, an effect associated with inhibition of motility and invasiveness. These results indicate that decitabine may prevent or reverse TJ leakiness.
Since TJ leakiness is associated with cancer progression and invasion, $\mathrm{TJ}$ tightening may have anti-metastatic activity (42); the anti-invasive activity of decitabine may be due, in part, to its ability to enhance TJ activity. The TJ structure represents the conglomerate of molecules that constitute, associate with, or regulate TJs, and a number of proteins, as components of TJs, were identified. Among these, 24 members of the claudin family, transmembrane proteins with extracellular domains, were identified. Claudins interact with other claudins to form homodimers or heterodimers to produce paired strands between cells to regulate paracellular permeability (6). Many previous studies indicate that disruption of TJs, with concomitant dysregulation of TJ proteins, is an early event in cancer cell invasion and metastasis, and the nature of the dysregulation is highly cancer type specific. For example, claudin-1 and claudin-7 are downregulated in invasive ductal carcinomas of the breast, as well as in most established breast cancer cell lines (43). However, claudin-3 and -4 are overexpressed in breast cancers (43-45), and other cancers, including gastric (46), ovarian (7), and pancreatic cancer (47). Conversely, 'knockdown' of these two claudins (claudin-3 and -4) inhibited the invasiveness of cancer cells (11). We also recently showed that claudin-1 played a causal role in acquiring invasive capacity in human liver cells, which was associated with increased expression of MMP-2. However, small interfering RNA targeting of claudin-1 in invasive hepatocellular carcinoma cells completely inhibited cell invasion (13). These observations indicate that claudins are dysregulated in many types of cancers, and may prove to be useful biomarkers for detecting and diagnosing certain cancers. Interestingly, Miyamori et al (48) reported claudin promotes activation of pro-MMP-2 mediated by membranetype MMPs. Agarwal et al (11)reported the overexpression of claudin-3 and -4 proteins is associated with increased MMP-2 activity. Recently, Ip et al (49) also showed downregulation of claudin-10 reduced MMP activity in human hepatocarcinoma cells. These reports imply a close relationship between MMP activity, overexpression of claudin, and metastasis of cancer cells. Therefore, we investigated the effects of decitabine on the level of claudin family members, and the data showed that decitabine significantly inhibited expression of claudin proteins such as claudin-2, -3 , and -4 at the transcriptional and translation levels (Fig. 5). The data suggested that the anti-invasive activity of decitabine was associated with the tightening of TJs through downregulation of claudin family members.

In addition, many reports have demonstrated that PI3K/Akt plays an important role in tumor development and progression through induction of epithelial-mesenchymal transition and achievement of invasive properties (50-53). In addition, MMP-2 and -9 expression has been critically associated with the PI3K/ Akt pathway (54). Therefore, we tested the effect of decitabine on the activities of the PI3K/Akt signaling pathway. The results demonstrated that decitabine inhibited phosphorylation of Akt after 12-h treatment guessing that the anti-invasive effects of decitabine were associated with downregulation of Akt phosphorylation (Fig. 6A). Furthermore, decitabine treatment resulted in significant blockage of LPS-induced Akt phosphorylation, cell motility, and invasion (Figs. 6 and 7). The data indicated that LPS-induced invasiveness mediated by suppressing the PI3K/Akt pathway, and anti-invasive effects 
by decitabine were mediated at least in part by the inactivation of the PI3K/Akt pathway, associated with TJs tightening.

In this study, although additional in vivo studies are needed to establish the role of decitabine as an anti-metastatic agent for treating cancer, we confirmed that decitabine inhibits cell motility and invasion of AGS human gastric cancer cells by increasing TJ activity and downregulation of MMP activity via inactivation of the PI3K/AKT signaling pathway.

\section{Acknowledgements}

This study was supported by the Basic Science Research Program through the National Research Foundation of Korea (NRF) funded by the Ministry of Education, Science, and Technology (2010-0001730), Republic of Korea.

\section{References}

1. Momparler RL: Epigenetic therapy of cancer with 5-aza2'-deoxycytidine (decitabine). Semin Oncol 32: 443-451, 2005.

2. Gassmann P, Enns A and Haier J: Role of tumor cell adhesion and migration in organ-specific metastasis formation. Onkologie 27: 577-582, 2004

3. Soler AP, Miller RD, Laughlin KV, Carp NZ, Klurfeld DM and Mullin JM: Increased tight junctional permeability is associated with the development of colon cancer. Carcinogenesis 20: 1425-1431, 1999.

4. Schneeberger EE and Lynch RD: The tight junction: a multifunctional complex. Am J Physiol Cell Physiol 286: 1213-1228, 2004.

5. Ruffer $\mathrm{C}$ and Gerke V: The C-terminal cytoplasmic tail of claudins 1 and 5 but not its PDZ-binding motif is required for apical localization at epithelial and endothelial tight junctions. Eur J Cell Biol 83: 135-144, 2004.

6. Morin PJ: Claudin proteins in human cancer: promising new targets for diagnosis and therapy. Cancer Res 65: 9603-9606, 2005.

7. Rangel LB, Agarwal R, D'Souza T, Pizer ES, Alò PL, Lancaster WD, Gregoire L, Schwartz DR, Cho KR and Morin PJ: Tight junction proteins claudin-3 and claudin- 4 are frequently overexpressed in ovarian cancer but not in ovarian cystadenomas. Clin Cancer Res 9: 2567-2575, 2003.

8. Mees ST, Mennigen R, Spieker T, Rijcken E, Senninger N, Haier $\mathrm{J}$ and Bruewer M: Expression of tight and adherens junction proteins in ulcerative colitis associated colorectal carcinoma: upregulation of claudin-1, claudin-3, claudin-4 and beta-catenin Int J Colorectal Dis 24: 361-368, 2009.

9. Ouban A and Ahmed AA: Claudins in human cancer: a review. Histol Histopathol 25: 83-90, 2010.

10. Jung H, Jun KH, Jung JH, Chin HM and Park WB: The expression of claudin-1, claudin-2, claudin-3, and claudin-4 in gastric cancer tissue. J Surg Res 167: e185-191, 2011.

11. Agarwal R, D'Souza T and Morin PJ: Claudin-3 and claudin-4 expression in ovarian epithelial cells enhances invasion and is associated with increased matrix metalloproteinase-2 activity. Cancer Res 65: 7378-7385, 2005.

12. Sun C, Yi T, Song X, Li S, Qi X, Chen X, Lin H, He X, Li Z, Wei Y and Zhao X: Efficient inhibition of ovarian cancer by short hairpin RNA targeting claudin-3. Oncol Rep 26: 193-200, 2011.

13. Yoon CH, Kim MJ, Park MJ, Park IC, Hwang SG, An S, Choi YH, Yoon $\mathrm{G}$ and Lee SJ: Claudin-1 acts through c-Abl-protein kinase Cdelta (PKCס) signaling and has a causal role in the acquisition of invasive capacity in human liver cells. J Biol Chem 285: 226-233, 2010.

14. Duffy MI, Maguire TM, Hill A, McDermott E and O'Higgins N: Metalloproteinases: role in breast carcinogenesis, invasion and metastasis. Breast Cancer Res 2: 252-257, 2000.

15. Vihinen P, Ala-aho R and Kähäri VM: Matrix metalloproteinases as therapeutic targets in cancer. Curr Cancer Drug Targets 5: 203-220, 2005.

16. Schwartz GK: Invasion and metastases in gastric cancer: in vitro and in vivo models with clinical correlations. Semin Oncol 23: 316-324, 1996.
17. Yasui W, Oue N, Aung PP, Matsumura S, Shutoh M and Nakayama H: Molecular-pathological prognostic factors of gastric cancer: a review. Gastric Cancer 8: 86-94, 2005.

18. Patra SK and Bettuzzi S: Epigenetic DNA-(cytosine-5-carbon) modifications: 5-aza-2'-deoxycytidine and DNA-demethylation. Biochemistry (Mosc) 74: 613-619, 2009.

19. Jubb AM, Bell SM and Quirke P: Methylation and colorectal cancer. J Pathol 195: 111-134, 2001.

20. Claus R, Almstedt M and Lübbert M: Epigenetic treatment of hematopoietic malignancies: in vivo targets of demethylating agents. Semin Oncol 32: 511-520, 2005.

21. Feinberg AP and Vogelstein B: Hypomethylation distinguishes genes of some human cancers from their normal counterparts. Nature 301: 89-92, 1983.

22. Goelz SE, Vogelstein B, Hamilton SR and Feinberg AP: Hypomethylation of DNA from benign and malignant human colon neoplasms. Science 228: 187-190, 1985.

23. Gomyo Y, Sasaki J, Branch C, Roth JA and Mukhopadhyay T: 5-aza-2'-deoxycytidine upregulates caspase-9 expression cooperating with p53-induced apoptosis in human lung cancer cells. Oncogene 23: 6779-6787, 2004.

24. Schnekenburger M, Grandjenette C, Ghelfi J, Karius T, Foliguet B, Dicato M and Diederich M: Sustained exposure to the DNA demethylating agent, 2'-deoxy-5-azacytidine, leads to apoptotic cell death in chronic myeloid leukemia by promoting differentiation, senescence, and autophagy. Biochem Pharmacol 81: 364-378, 2011.

25. Zhu W, Fu A, Hu J, Wang T, Luo Y, Peng M, Ma Y, Wei Y and Chen L: 5-Formylhonokiol exerts anti-angiogenesis activity via inactivating the ERK signaling pathway. Exp Mol Med 43: 146-152, 2011.

26. Grant-Tschudy KS and Wira CR: Effect of oestradiol on mouse uterine epithelial cell tumour necrosis factor-alpha release is mediated through uterine stromal cells. Immunology 115 : 99-107, 2005.

27. Song HY, Ju SM, Goh AR, Kwon DJ, Choi SY and Park J: Suppression of TNF-alpha-induced MMP-9 expression by a cellpermeable superoxide dismutase in keratinocytes. BMB Rep 44: 462-467, 2011.

28. Shukla S, Maclennan GT, Hartman DJ, Fu P, Resnick MI and Gupta S: Activation of PI3K-Akt signaling pathway promotes prostate cancer cell invasion. Int J Cancer 121: 1424-1432, 2007.

29. Chen JS, Wang Q, Fu XH, Huang XH, Chen XL, Cao LQ, Chen LZ, Tan HX, Li W, Bi J and Zhang LJ: Involvement of $\mathrm{PI} 3 \mathrm{~K} / \mathrm{PTEN} / \mathrm{AKT} / \mathrm{mTOR}$ pathway in invasion and metastasis in hepatocellular carcinoma: association with MMP-9. Hepatol Res 39: 177-186, 2009

30. Matrisian LM: The matrix-degrading metalloproteinases. Bioessays 14: 455-463, 1992.

31. Mook OR, Frederiks WM and Van Noorden CJ: The role of gelatinases in colorectal cancer progression and metastasis. Biochim Biophys Acta 1705: 69-89, 2004.

32. Uzui H, Harpf A, Liu M, Doherty TM, Shukla A and Chai N: Increased expression of membrane type 3-matrix metalloproteinase in human atherosclerotic plaque: role of activated macrophages and inflammatory cytokines. Circulation 106: 3024-3030, 2002.

33. Lambert E, Dasse E, Haye B and Petitfrere E: TIMPs as multifacial proteins. Crit Rev Oncol Hematol 49: 187-198, 2004.

34. Martin TA and Jiang WG: Loss of tight junction barrier function and its role in cancer metastasis. Biochim Biophys Acta 1788: 872-891, 2009.

35. Latorre IJ, Roh MH, Frese KK, Weiss RS, Margolis B and Javier RT: Viral oncoprotein-induced mislocalization of select PDZ proteins disrupts tight junctions and causes polarity defects in epithelial cells. J Cell Sci 118: 4283-4293, 2005

36. Gitter AH, Bendfeldt K, Schmitz H, Schulzke JD, Bentzel CJ and Fromm M: Epithelial barrier defects in HT-29/B6 colonic cell monolayers induced by tumor necrosis factor. Ann N Y Acad Sci 915: 193-203, 2000.

37. Verghese GM, Gutknecht MF and Caughey GH: Prostasin regulates epithelial monolayer function: cell-specific Gpld1mediated secretion and functional role for GPI anchor. Am J Physiol Cell Physiol 291: 1258-1270, 2006.

38. Van Deun K, Pasmans F, Van Immerseel F, Ducatelle R and Haesebrouck F: Butyrate protects Caco-2 cells from Campylobacter jejuni invasion and translocation. Br J Nutr 100: 480-484, 2008. 
39. Kim SO, Choi BT, Choi IW, Cheong J, Kim GY, Kwon TK, Kim ND and Choi YH: Anti-invasive activity of histone deacetylase inhibitors via the induction of Egr-1 and the modulation of tight junction-related proteins in human hepatocarcinoma cells. BMB Rep 42: 655-660, 2009.

40. Kim SO, Kwon JI, Jeong YK, Kim GY, Kim ND and Choi YH: Induction of Egr-1 is associated with anti-metastatic and antiinvasive ability of $\beta$-lapachone in human hepatocarcinoma cells. Biosci Biotechnol Biochem 71: 2169-2176, 2007.

41. Shin DY, Kim GY, Kim JI, Yoon MK, Kwon TK, Lee SJ, Choi YW, Kang HS, Yoo YH and Choi YH: Anti-invasive activity of diallyl disulfide through tightening of tight junctions and inhibition of matrix metalloproteinase activities in LNCaP prostate cancer cells. Toxicol In Vitro 24: 1569-1576, 2010.

42. Mullin JM, Agostino N, Rendon-Huerta E and Thornton JJ: Keynote review: epithelial and endothelial barriers in human disease. Drug Discov Today 10: 395-408, 2005.

43. Kominsky SL, Vali M, Korz D, Gabig TG, Weitzman SA, Argani P and Sukumar S: Clostridium perfringens enterotoxin elicits rapid and specific cytolysis of breast carcinoma cells mediated through tight junction proteins claudin 3 and 4 . Am J Pathol 164: 1627-1633, 2004.

44. Kominsky SL, Argani P, Korz D, Evron E, Raman V, Garrett E, Rein A, Sauter G, Kallioniemi OP and Sukumar S: Loss of the tight junction protein claudin-7 correlates with histological grade in both ductal carcinoma in situ and invasive ductal carcinoma of the breast. Oncogene 22: 2021-2033, 2003.

45. Tokés AM, Kulka J, Paku S, Szik A, Páska C, Novák PK, Szilák L, Kiss A, Bögi K and Schaff Z: Claudin-1, -3 and -4 proteins and mRNA expression in benign and malignant breast lesions: a research study. Breast Cancer Res 7: 296-305, 2005
46. Cunningham SC, Kamangar F, Kim MP, Hammoud S, Haque R, Iacobuzio-Donahue CA, Maitra A, Ashfaq R, Hustinx S, Heitmiller RE, et al: Claudin-4, mitogen activated protein kinase kinase 4, and stratifin are markers of gastric adenocarcinoma precursor lesions. Cancer Epidemiol Biomarkers Prev 15: 281-287, 2004.

47. Michl P, Barth C, Buchholz M, Lerch MM, Rolke M, Holzmann KH, Menke A, Fensterer H, Giehl K, Löhr M, et al: Claudin-4 expression decreases invasiveness and metastatic potential of pancreatic cancer. Cancer Res 63: 6265-6271, 2003.

48. Miyamori H, Takino T, Kobayashi Y, Tokai H, Itoh Y, Seiki M and Sato $\mathrm{H}$ : Claudin promotes activation of pro-matrix metalloproteinase- 2 mediated by membrane-type matrix metalloproteinases. J Biol Chem 276: 28204-28211, 2001.

49. Ip YC, Cheung ST, Lee YT, Ho JC and Fan ST: Inhibition of hepatocellular carcinoma invasion by suppression of claudin-10 in HLE cells. Mol Cancer Ther 6: 2858-2867, 2007.

50. Reddy KB, Nabha SM and Atanaskova N: Role of MAP kinase in tumor progression and invasion. Cancer Metastasis Rev 22: 395-403, 2003.

51. Samuels $\mathrm{Y}$ and Ericson K: Oncogenic PI3K and its role in cancer. Curr Opin Oncol 18: 77-82, 2006.

52. Thiery JP, Acloque H, Huang RY and Nieto MA: Epithelialmesenchymal transitions in development and disease. Cell 139: 871-890, 2009.

53. Yilmaz M and Christofori G: EMT, the cytoskeleton, and cancer cell invasion. Cancer Metastasis Rev 28: 15-33, 2009.

54. Chakraborti S, Mandal M, Das S, Mandal A and Chakraborti T: Regulation of matrix metalloproteinases: an overview. Mol Cell Biochem 253: 269-285, 2003. 